\title{
Operative Debridement of Pressure Ulcers
}

\author{
Jessica Schiffman • Michael S. Golinko • \\ Alan Yan · Anna Flattau · Marjana Tomic-Canic • \\ Harold Brem
}

Published online: 8 May 2009

(c) The Author(s) 2009. This article is published with open access at Springerlink.com

\begin{abstract}
Background Infection in severe pressure ulcers can lead to sepsis with a 6-month mortality as high as $68 \%$.

Methods Operative records of 142 consecutive operative debridements on 60 patients in a dedicated wound healing inpatient unit were reviewed, from the Wound Electronic Medical Record, for identification of key steps in debridement technique, mortality, unexpected returns, and time to discharge following debridement.

Results The mean age of the patients was 73.1 years, and $45 \%$ were men. Most wounds (53\%) were located on the hip (ischial or trochanteric); others were on the sacrum (32\%) and the heels (14\%). The mean initial wound area prior to debridement was $14.0 \mathrm{~cm}^{2}$, and $83 \%$ of debridements were performed on stage IV pressure ulcers. The postoperative
\end{abstract}

\section{J. Schiffman}

Johns Hopkins University School of Medicine, Baltimore, MD, USA

\section{S. Golinko}

Department of Surgery, New York University School of Medicine, New York, NY, USA

A. Yan $\cdot$ H. Brem $(\bowtie)$

Division of Wound Healing \& Regenerative Medicine, Helen \& Martin Kimmel Wound Center, Department of Surgery, New

York University School of Medicine, New York, NY, USA

e-mail: Harold.brem@nyumc.org

URL: www.NYUwound.org

\section{A. Flattau}

Department of Family \& Social Medicine, Montefiore Medical Center, Bronx, NY, USA

M. Tomic-Canic

Department of Dermatology \& Cutaneous Surgery, University of Miami Miller School of Medicine, Miami, FL, USA hospital stay averaged 4.1 days. Key steps in the technique included (1) exposure of areas of undermining by excising overlying tissue; (2) removal of callus from wound edges; (3) removal of all grossly infected tissue; and (4) obtaining a biopsy of the deep tissue after debridement of all nonviable or infected tissue for culture and pathology to determine the presence of infection, fibrosis, and granulation tissue. There was one death 9 days post-debridement of a sacral ulcer and one unplanned return to the operating room for bleeding 8 days post-debridement.

Conclusions Operative debridement of pressure ulcers is safe, despite the medical co-morbidities in patients with severe pressure ulcers. Proper debridement technique may prevent sepsis and death in patients with multiple comorbid conditions.

\section{Introduction}

Pressure ulcers commonly affect bed-bound patients with acute or chronic illnesses [1]. The prevalence of pressure ulcers in the United States is as high as $27.7 \%$ in long-term care settings [2]. Hospitalizations directly related to pressure ulcers have increased by $63 \%$ over a 10 -year period, and septicemia is the most common admitting diagnosis [3]. Mortality exceeds $68 \%$ in certain settings[4]. Because pressure ulcers are commonly associated with co-morbid conditions such as dementia, spinal cord injury, stroke, or other acute illness in hospitalized patients [3], the true prevalence may be underestimated. According to the Center for Medicaid and Medicare Services (CMS), the average hospital charge per pressure ulcer patient exceeds $\$ 43,000$. The cost to acute care hospitals has increased significantly in light of a recent announcement by the CMS 
that classified severe pressure ulcers developed in the hospital as a "never event," and consequently care for these hospital-acquired stage III or IV pressure ulcers will no longer be reimbursed [5].

Pressure ulcers are caused by multiple pathogenic mechanisms, including direct pressure $[6,7]$ and microcirculatory ischemia [8]. Despite a rising incidence of pressure ulcers in the United States, the molecular mechanisms behind their development have not been fully elucidated. Tissue changes in response to pressure may include structural changes in the dermis and cellular deformation followed by cytoskeletal and extracellular matrix alterations $[9,10]$. The epidermis of the non-healing edge of the pressure ulcers, as well as that of venous and diabetic foot ulcers, shows increased expression of $c$-myc and activation of nuclear $\beta$-catenin that leads to formation of thick, hyperproliferative epidermis [11].

When patients present with stage III or IV ulcers, treatment is directed toward prevention and management of secondary complications-especially sepsis-and promotion of wound healing. Removal of devitalized tissue is necessary for wound healing [12], because moist necrotic tissue provides a medium for infection [13] that triggers an inflammatory response [14] and eventually results in impaired wound healing [15]. Sharp debridement removes this source of infection and sepsis [16]. Small or superficial wounds can be debrided at the bedside, but debridement in the operating room is often necessary for stage III and IV ulcers.

Operative debridement to treat pressure ulcers has been extensively described, with the first report of operative debridement to adequately prepare the wound bed for healing published in 1950 by Cannon et al. [17]. Since then, a number of reports have detailed certain aspects of the surgical technique [18-25], although few have offered a step-by-step description and subsequent outcomes. Regardless of whether a pressure ulcer heals subsequently by myocutaneous flap coverage or by secondary intention, surgical debridement to remove infection is an integral part of wound bed preparation.

The indications for the operative procedure include, but are not limited to, the following:

1. Removal of the source of sepsis, defined as systemic inflammatory response syndrome (SIRS) in the presence of infection. (Diagnostic criteria for SIRS include any two of the following: temperature 38 or $36^{\circ} \mathrm{C}$, heart rate $>90 \mathrm{bpm}$, respiratory rate $\geq 20$ breaths/ min or $\mathrm{PaCO}_{2} \leq 32 \mathrm{mmHg}$ or mechanical ventilation, and white blood cell count $\geq 12,000 / \mu \mathrm{l}$ or $\leq 4,000 / \mu \mathrm{l}$ or $\geq 10 \%$ band forms [26]).

2. Removal of local infection to decrease bacterial burden, to reduce the probability of resistance from antibiotic treatment, and to obtain accurate cultures [27].

3. Collection of deep cultures taken after debridement from the tissue left behind to evaluate persistent infection and requirements for systemic antibiotic treatment [27].

4. Stimulation of the wound bed to promote healing and prepare for a skin graft or flap [28].

The purpose of the present study is to describe a technique for operative debridement of severe pressure ulcers. This procedure results in low mortality despite the multiple co-morbidities of pressure ulcer patients.

\section{Materials and methods}

Operative reports for 142 consecutive debridements from 60 patients were reviewed. All patients were treated at a single university-based, tertiary care hospital by a single surgeon and admitted to a dedicated wound healing inpatient unit from January 2004 to December 2006.

Patient age, gender, wound location, wound area, and pressure ulcer staging at the time of operative debridement were abstracted from the Wound Electronic Medical Record. The number of debridements per wound was calculated. The time to discharge after debridement was calculated per operation. If debridement was performed on the same wound on subsequent occasions during the same admission, the time to discharge was calculated from the day of the first debridement. Criteria defining a safe operation included (1) no unplanned return to the operating room during hospital stay and (2) no mortality prior to discharge from the hospital. Descriptive statistics were tabulated with MS Excel 2007 (Microsoft Corporation, Redmond, WA). This study was approved by the Institutional Review Board.

\section{Results}

Key steps in the operative technique

Prior to operation, the surgeon explored the wound for undermining, using a swab or gloved finger (Fig. 1). Undermining is defined by CMS as the destruction of tissue or ulceration extending under the skin edges such that the pressure ulcer measures larger at its base than at the skin surface [29]. For patients with sacral or ischial pressure ulcers, a rectal exam was performed, and the area overlying the rectum was indicated with a marking pen. During debridement, the perirectal fibrinous tissue may be 


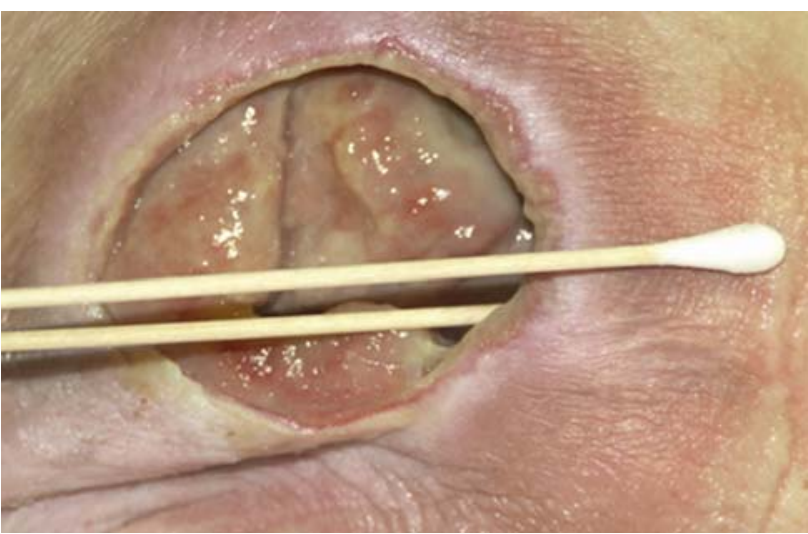

Fig. 1 Exploration of the wound for undermining can be performed with a gloved finger or a sterile cotton swab, as depicted here

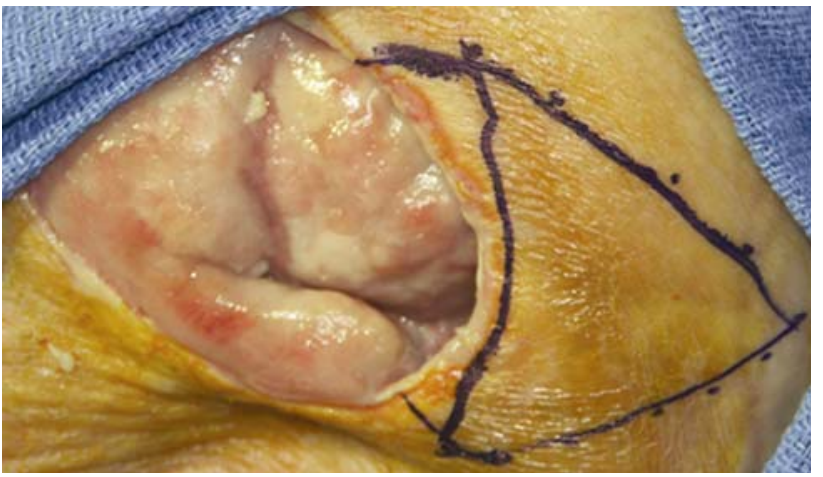

Fig. 2 Outline of triangular segment of undermining

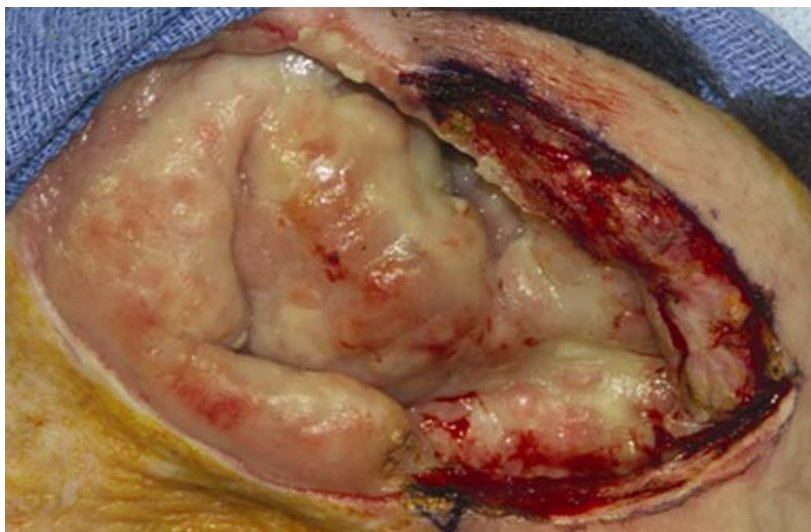

Fig. 3 Triangular segment of skin covering undermining removed

removed, but deep penetration to the rectal muscle should be avoided.

The wound was widely prepped in order to capture the outermost area of undermining. Segments of the overlying tissue were resected to expose areas of undermining. This tissue usually includes healthy-appearing skin as well as the underlying subcutaneous tissue and fascia, and it is resected in triangular segments, using electrocautery to minimize bleeding. As Figs. 2 and 3 illustrate, the apex of

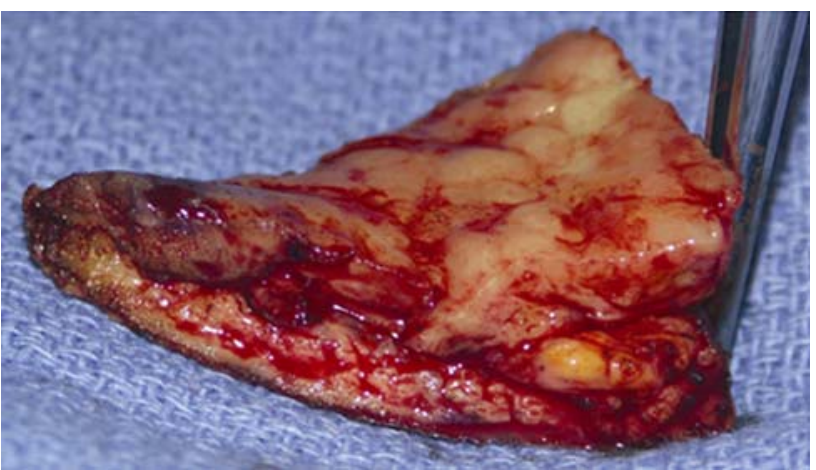

Fig. 4 Triangular segment of skin removed and sent to pathology

the triangle should extend to the outermost circumference of the area of undermining, and the base of the triangle should be adjacent to the outer edge of the wound. The resected area should be restricted to the minimum amount needed to expose the pockets of undermining and to allow for debridement of underlying necrotic tissue and full exposure of the wound bed. This resection will also allow for deep packing in dressing changes. Although healthy skin is removed, this skin typically heals faster than tissue at the base of the wound (Fig. 4).

All necrotic, infected, and nonhealing tissue from the wound base is debrided using a scalpel, electrocautery, rongeur, or curette. This may include subcutaneous tissue, muscle, tendon, and/or bone. Removal of this material is achieved by grasping the tissue with an Alice clamp or other suitable clamp and layer-by-layer excision with a scalpel. Caution should be taken because nonviable tissue, including necrotic muscle, can bleed. Soft bone usually is an indication of osteomyelitis and should be debrided with a rongeur. Adequate debridement is defined by the absence of infection and fibrosis in the wound bed, as determined by culture and pathology.

Routine pathology

Routine hematoxylin and eosin (H\&E) staining of debridement specimens is helpful in determining the appropriate depth of debridement i.e. all necrotic, infected, and nonhealing tissue is debrided. Figure 5 illustrates the pathology for the wound debridement shown. The area of skin over undermining contains granulation tissue $(\mathrm{G})$, which contains multiple inflammatory cells and newly formed blood vessels. However, deep to the granulation tissue is an area of fibrosis (F), which contains acellular woven strands of collagen. This scar tissue indicates that further debridement is needed to reach healthy granulation tissue. Skeletal muscle (M) is often encountered (as shown in Fig. 5b), surrounded by areas of fibrosis (F) and granulation tissue $(\mathrm{G})$. The goal is to remove all infection and 
Fig. 5 a Low-power view of excised skin over area of undermining. The superior black arrow indicates hyperkeratotic and thickened skin, and the inferior arrow indicates the ulcer bed. A layer of granulation tissue $(\mathrm{G})$ was present as deeper fibrosis (F). b Pressure ulcer debridement often may extend and require removal of scarred muscle (M). $F$ regions of fibrosis; $G$ an area of granulation tissue. c A fragment of viable bone (B) as evidenced by nucleated osteocytes (black circle) and adjacent fibrosis $(\mathrm{F})$

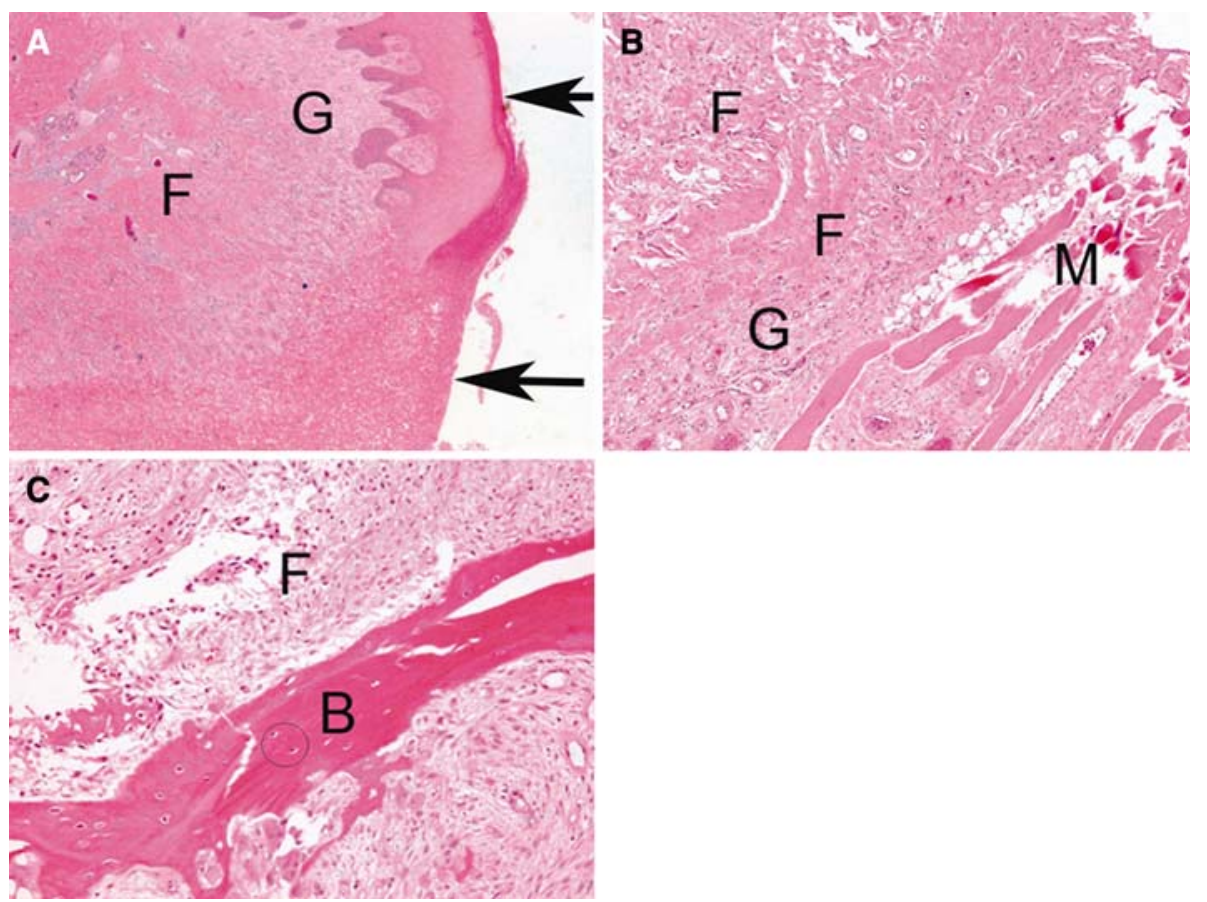

scar tissue from the deepest level of debridement, which usually involves bone in stage IV pressure ulcers. As shown in Fig. 5c, viable bone (B) is evident, as indicated by the multiple nuclei (encircled) surrounded by granulation tissue $(\mathrm{G})$, and there is no evidence of infection, i.e. osteomyelitis. Occasionally, fibrotic bone is encountered, and this finding may have potentially different implications for healing than osteomyelitis.

After a deep tissue specimen following debridement has been sent for pathology and culture, hemostasis is achieved. Injuries to blood vessels are repaired with absorbable sutures in a figure-of-eight or locked running technique. Manual pressure stops most capillary bleeding. Further hemostasis can be achieved by a variety of methods including electrocautery, Gelfoam thrombin (Pfizer, New York, NY) [30, 31], or Surgicel (Johnson \& Johnson, Piscataway, NJ) [32]. Our preference is Floseal ${ }^{\circledR}$ (Baxter, Deerfield, IL) [31] (Figs. 6, 7). The wound is then packed with a microfibrillar collagen [33] such as Instat (Johnson \& Johnson, Piscataway, NJ) (Fig. 7), after which sterile gauze and a Tegaderm dressing (3 M, St Paul, MN) are applied.

\section{Postoperative wound management}

Dressings are left in place for up to 5 days after surgery depending on the amount of serous or serosanguinous drainage. Once the postoperative dressing is removed, topical dressings such as Silvadene [34], collagenase (Worthington Biochemical Corporation, Lakewood, NJ) [35], or Iodosorb (Smith \& Nephew, Hull, UK) [36] will provide a moist wound environment for healing [37].

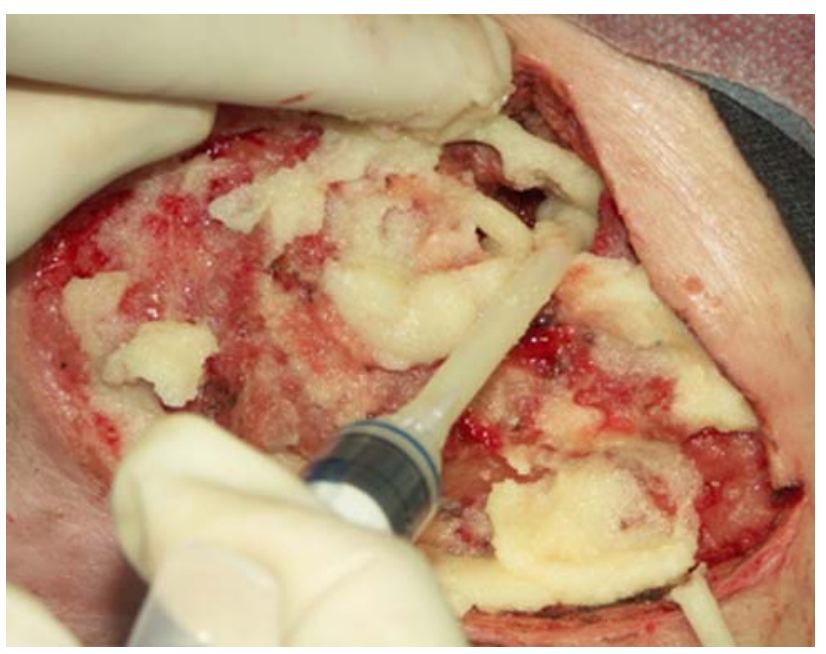

Fig. 6 Application of Floseal to achieve hemostasis

Vacuum-assisted closure (VAC) therapy (V.A.C.; KCI, San Antonio, TX) can be considered [38] and employed in accordance to published guidelines [39]. Pressure ulcer patients require pressure-relief mattresses. Patients with heel ulcers require offloading devices such as heel lifts or MultiPodus boots (RCAI, St. Petersburg, FL). For continuing wound treatment, patients benefit from either home care (e.g., nurses) or nursing home services [37].

Wound characteristics and operative safety

This study reviews 142 debridements performed on 60 patients (45\% of them men). The initial ulcer area prior to 


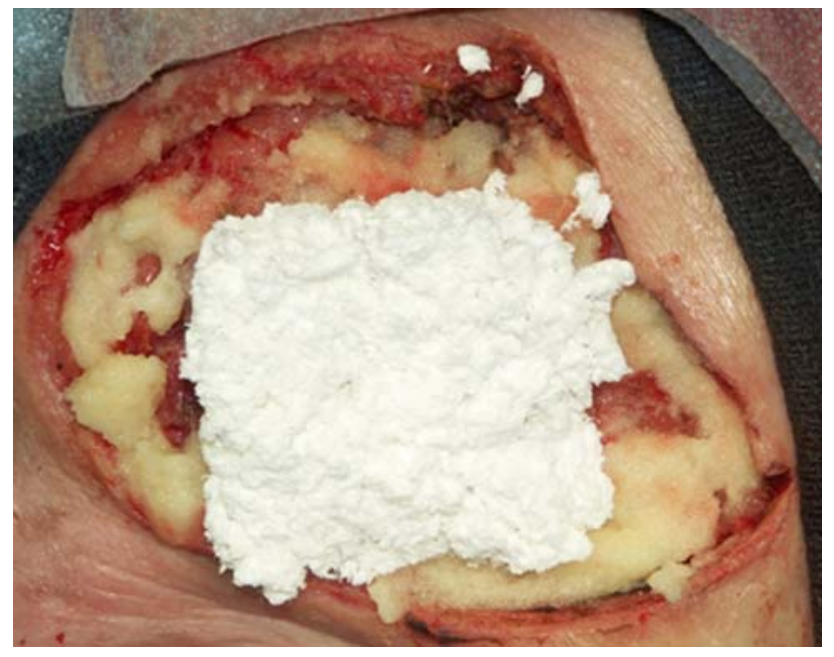

Fig. 7 Application of collagen to achieve hemostasis

debridement was $14 \pm 18.9 \mathrm{~cm}^{2}$. Because patients often had multiple wounds, operative debridement was performed on 77 stage IV, 6 stage III, 4 stage II, and 37 unstageable ulcers. Results are summarized in Table 1.

There was one postoperative death in this series. A 79year-old man died 9 days after undergoing debridement of a sacral ulcer. There was also one unplanned return to the operating room for bleeding 8 days post-debridement of a sacral ulcer in an 82-year-old woman.

\section{Discussion}

Patients with stage III and IV pressure ulcers comprise a population with multiple co-morbidities and high mortality, often requiring multiple hospital admissions [40, 41]. In this report we document the effectiveness of operative debridement-even in patients with severe pressure ulcers-showing that it can be performed safely and result in low mortality rates.

Table 1 Descriptive table for surgical debridement of pressure ulcers

Percentage of total

\begin{tabular}{ll}
\hline Wound characteristics $(n=91)$ & \\
Hip (ischial + trochanteric) & $53 \%$ \\
Sacrum & $32 \%$ \\
Heel & $14 \%$ \\
Other & $1 \%$ \\
Debridement characteristics $(n=142)$ & \\
Mean age at debridement (years) & $73.1 \pm 17$ \\
Mean initial stage at debridement & $3.6 \pm 0.7$ \\
Percentage of stage IV debrided & $83 \%$ \\
Mean initial wound area \pm SD $\left(\mathrm{cm}^{2}\right)$ & $14.0 \pm 18.9$ \\
Mean days to discharge after debridement & $4.1 \pm 4.5$ \\
\hline
\end{tabular}

Most of the patients in this study required multiple debridements because of the severity of their ulcers. In this group, we observed a large incidence of undermining (Fig. 1). Resection of undermined tissue is advocated because of the underlying pathology that often accompanies this finding. As indicated in Fig. 6a, which illustrates the H\&E staining of the skin over the specimen shown in Fig. 4, fibrosis $(F)$ is visible deep to the granulation tissue. The granulation tissue $(\mathrm{G})$ of the ulcer bed is indicated by the lower black arrow, and it extends to the area underneath the acanthotic and hyperkeratotic tissue epithelium, as indicated by the top arrow of undermining. Hyperkeratosis is indicative of abnormal keratinocyte migration and differentiation $[42,43]$, and in pressure ulcers, hyperkeratotic epidermis may prevent the ulcer from healing and should be resected [11].

When a wound is debrided for the first time, the extent of debridement depends on the gross appearance of the tissue. If the patient has undergone prior debridements, pathology results from previous surgeries will be crucial in identifying areas of remaining nonviable tissue or scar, and thereby determining the extent of subsequent debridements. The pathology report will confirm the viability of remaining tissue-e.g., if it contains well-vascularized granulation tissue free of infection and scar. Cultures taken from the same area will reveal any remaining bacteria. Exposed bone should always be sent for culture to assist in the diagnosis and treatment of osteomyelitis.

Because of the high incidence of medical co-morbidities in patients with pressure ulcers, patients may be coagulopathic from medication, chronic diseases, or sepsis. Patients at risk for cardiac ischemia should be treated perioperatively with beta-blockers, according to the American College of Cardiology/American Heart Association guidelines [44]. Patients receiving antiplatelet agents should continue these medications and not compromise their therapeutic or prophylactic effects. If surgery is performed while the patient is being anticoagulated in order to remove a source of sepsis, a limited debridement may be done, with the intention to return to the operating room for further serial procedures. The surgeon should be prepared to use multiple hemostatic agents (Figs. 6,7) in addition to judicious cauterization and manual pressure.

There is extensive literature on definitive closure of pressure ulcers with flaps, although most acutely ill patients requiring debridement are not candidates for myocutaneous flaps. The purpose of the debridement technique described here is to remove sources of sepsis and to stimulate wound healing.

Although operative mortality was low in this study (2\%), long-term mortality may be as high as $68 \%$ following debridement [45]. Hospitalized patients with severe pressure ulcers generally have multiple medical co-morbidities, 
including osteomyelitis, and are at a greater risk of death $[4,46]$. In patients with heel ulcers, ischemia should be assessed prior to operation by obtaining an ankle-brachial index and pulse volume recording [47]. If ischemia is present, surgical debridement may be necessary to remove actively infected tissue that is a potential source of sepsis; however, elective procedures should be deferred until after revascularization has been achieved.

Acute illness from systemic effects of infection is common. As in all surgeries, preoperative assessment should focus on optimizing the patient for the procedure. Patients are frequently dehydrated and require fluid resuscitation and close monitoring of fluid status by measurement of fluid intake and output, Foley catheterization, calculation of fractional excretion of sodium, and measurement of central venous pressure.

The primary physician should initiate discussions with the patient about palliative care and surgical care, with surgical referral completed only after the decision to operate has been made. The surgeon can then assess the nature, risks, and benefits of operative debridement, and can discuss in detail with the patient. Once debridement has been performed, intensive, long-term follow-up is required to monitor healing rate, manage local wound care, detect wound infections early, and plan for repeat debridement if necessary. Close coordination between inpatient and outpatient management is crucial.

The surgical technique described here is safe for hospitalized patients with severe pressure ulcers. Further study would be of interest to measure outcomes such as healing rates and mortality, particularly in the diabetic and elderly populations. Moreover, randomized controlled trials correlating the histopathology and culture of debridement with outcomes are also warranted.

Acknowledgments This work was supported by grants from the National Institutes of Health to H.B. (LM008443) and to M.T.C. (AG030673). The authors are grateful to all members of the Division of Wound Healing and Regenerative Medicine for their support and dedication to this project, to Dr. Renata Joffe for reviewing all operative pathology and histologic descriptions in this article, and to Robert Rennert for the literature search and updating of references.

Open Access This article is distributed under the terms of the Creative Commons Attribution Noncommercial License which permits any noncommercial use, distribution, and reproduction in any medium, provided the original author(s) and source are credited.

\section{References}

1. Baumgarten M, Margolis DJ, Localio AR, Kagan SH, Lowe RA, Kinosian B, Holmes JH, Abbuhl SB, Kavesh W, Ruffin A (2006) Pressure ulcers among elderly patients early in the hospital stay. $\mathbf{J}$ Gerontol A Biol Sci Med Sci 61:749-754
2. Horn SD, Bender SA, Bergstrom N, Cook AS, Ferguson ML, Rimmasch HL, Sharkey SS, Smout RJ, Taler GA, Voss AC (2002) Description of the National Pressure Ulcer Long-Term Care Study. J Am Geriatr Soc 50:1816-1825

3. Russo A, Elixhauser A (2006) Hospitalizations related to pressure sores, 2003. Healthcare Cost and Utilization Project. http://www. ahrq.gov/data/hcup/. Accessed 25 March 2009

4. Brown G (2003) Long-term outcomes of full-thickness pressure ulcers: healing and mortality. Ostomy Wound Manage 49:42-50

5. Center for Medicare \& Medicaid Services. Eliminating serious, preventable, and costly medical errors-never events. http:// www.cms.hhs.gov/apps/media/press/release.asp?Counter=1863. Accessed 7 April 2009

6. Gawlitta D, Li W, Oomens CW, Baaijens FP, Bader DL, Bouten CV (2007) The relative contributions of compression and hypoxia to development of muscle tissue damage: an in vitro study. Ann Biomed Eng 35:273-284

7. Supp DM, Boyce ST (2005) Engineered skin substitutes: practices and potentials. Clin Dermatol 23:403-412

8. Tsuji S, Ichioka S, Sekiya N, Nakatsuka T (2005) Analysis of ischemia-reperfusion injury in a microcirculatory model of pressure ulcers. Wound Repair Regen 13:209-215

9. Bouten CV, Oomens CW, Baaijens FP, Bader DL (2003) The etiology of pressure ulcers: skin deep or muscle bound? Arch Phys Med Rehabil 84:616-619

10. Edsberg LE (2007) Pressure ulcer tissue histology: an appraisal of current knowledge. Ostomy Wound Manage 53:40-49

11. Stojadinovic O, Brem H, Vouthounis C, Lee B, Fallon J, Stallcup M, Merchant A, Galiano RD, Tomic-Canic M (2005) Molecular pathogenesis of chronic wounds: the role of beta-catenin and cmyc in the inhibition of epithelialization and wound healing. Am J Pathol 167:59-69

12. Agren M, Stromberg H (1985) Topical treatment of pressure ulcers: a randomized comparative trial of Varidase and zinc oxide. Scand J Plast Reconstr Surg 19:97-100

13. Galpin J, Chow A, Bayer A, Guze L (1976) Sepsis associated with decubitus ulcers. Am J Med 61:346-350

14. Longe R (1986) Current concepts in clinical therapeutics: pressure sores. Clin Pharm 5:669-681

15. Bergstrom N (1994) AHCPR supported clinical practice guidelines in treatment of pressure ulcers. National Library of Medicine, Bethesda, MD

16. Niezgoda JA, Mendez-Eastman S (2006) The effective management of pressure ulcers. Adv Skin Wound Care 19(Suppl 1):3-15

17. Cannon B, O’Leary JJ, O'Neil JW, Steinsieck R (1950) An approach to the treatment of pressure sores. Ann Surg 132:760 778

18. Black JM (1994) Surgical management of pressure ulcers. Nurs Clin North Am 29:801-808

19. Black JM, Black SB (1987) Surgical management of pressure ulcers. Nurs Clin North Am 22:429-438

20. Bunt TJ (1983) Successful management of decubitus ulcers by the general surgeon. South Med J 76:453-455

21. Herceg SJ, Harding RL (1978) Surgical treatment of pressure ulcers. Arch Phys Med Rehabil 59:193-200

22. Linder RM, Morris D (1990) The surgical management of pressure ulcers: a systematic approach based on staging. Decubitus 3:32-38

23. Netscher D, Clamon J, Fincher L, Thompson R (1996) Surgical repair of pressure ulcers. Plast Surg Nurs 16:225-233, 239

24. Niazi ZB, Salzberg CA (1997) Operative repair of pressure ulcers. Clin Geriatr Med 13:587-597

25. Niazi ZB, Salzberg CA (1997) Surgical management of pressure ulcers. Ostomy Wound Manage 43:44-48, 50-42

26. Levy MM, Fink MP, Marshall JC, Abraham E, Angus D, Cook D, Cohen J, Opal SM, Vincent JL, Ramsay G (2003) 2001 SCCM/ 
ESICM/ACCP/ATS/SIS international sepsis definitions conference. Crit Care Med 31:1250-1256

27. Garner J, Javis W, Emori T, Horan T, Hughes J (1988) CDC definitions for nosocomial infections. Am J Infect Control 16:128-140

28. Sorensen J, Jorgensen B, Gottrup F (2004) Surgical treatment of pressure ulcers. Am J Surg 188:42S-51S

29. Center for Medicare \& Medicaid Services. CMS manual system-guidance to surveyors for long term care facilities. http://www.cms.hhs.gov/transmittals/Downloads/R4SOM.pdf. Accessed 7 April 2009

30. Bouma BN, Mosnier LO (2006) Thrombin activatable fibrinolysis inhibitor (TAFI) — how does thrombin regulate fibrinolysis? Ann Med 38:378-388

31. Weaver FA, Hood DB, Zatina M, Messina L, Badduke B (2002) Gelatin-thrombin-based hemostatic sealant for intraoperative bleeding in vascular surgery. Ann Vasc Surg 16:286-293

32. Sirlak M, Eryilmaz S, Yazicioglu L, Kiziltepe U, Eyileten Z, Durdu MS, Tasoz R, Eren NT, Aral A, Kaya B, Akalin H (2003) Comparative study of microfibrillar collagen hemostat (Colgel) and oxidized cellulose (Surgicel) in high transfusion-risk cardiac surgery. J Thorac Cardiovasc Surg 126:666-670

33. De Vries HJ, Mekkes JR, Middelkoop E, Hinrichs WL, Wildevuur CR, Westerhof W (1993) Dermal substitutes for full-thickness wounds in a one-stage grafting model. Wound Repair Regen 1:244-252

34. Kucan JO, Robson MC, Heggers JP, Ko F (1981) Comparison of silver sulfadiazine, povidone-iodine and physiologic saline in the treatment of chronic pressure ulcers. J Am Geriatr Soc 29:232235

35. Lee LK, Ambrus JL (1975) Collagenase therapy for decubitus ulcers. Geriatrics 30(91-93):97-98

36. Moberg S, Hoffman L, Grennert ML, Holst A (1983) A randomized trial of cadexomer iodine in decubitus ulcers. $\mathrm{J}$ Am Geriatr Soc 31:462-465

37. Brem H, Lyder C (2004) Protocol for the successful treatment of pressure ulcers. Am J Surg 188:9-17

38. Schuster R, Moradzadeh A, Waxman K (2006) The use of vacuum-assisted closure therapy for the treatment of a large infected facial wound. Am Surg 72:129-131
39. Whitney J, Phillips L, Aslam R, Barbul A, Gottrup F, Gould L, Robson MC, Rodeheaver G, Thomas D, Stotts N (2006) Guidelines for the treatment of pressure ulcers. Wound Repair Regen 14:663-679

40. Schryvers OI, Stranc MF, Nance PW (2000) Surgical treatment of pressure ulcers: 20-year experience. Arch Phys Med Rehabil 81:1556-1562

41. Allman RM, Goode PS, Burst N, Bartolucci AA, Thomas DR (1999) Pressure ulcers, hospital complications, and disease severity: impact on hospital costs and length of stay. Adv Wound Care 12:22-30

42. Brem H, Stojadinovic O, Diegelmann RF, Entero H, Lee B, Pastar I, Golinko M, Rosenberg H, Tomic-Canic M (2007) Molecular markers in patients with chronic wounds to guide surgical debridement. Mol Med 13:30-39

43. Stojadinovic O, Pastar I, Vukelic S, Mahoney MG, Brennan D, Krzyzanowska A, Golinko M, Brem H, Tomic-Canic M (2008) Deregulation of keratinocyte differentiation and activation: a hallmark of venous ulcers. J Cell Mol Med 12:2675-2690

44. Fleisher LA, Beckman JA, Brown KA, Calkins H, Chaikof EL, Fleischmann KE, Freeman WK, Froehlich JB, Kasper EK, Kersten JR et al (2007) ACC/AHA 2006 guideline update on perioperative cardiovascular evaluation for noncardiac surgery: focused update on perioperative beta-blocker therapy-a report of the American College of Cardiology/American Heart Association Task Force on Practice Guidelines (Writing Committee to Update the 2002 Guidelines on perioperative cardiovascular evaluation for noncardiac surgery). Anesth Analg 104:15-26

45. Kuwahara M, Tada H, Mashiba K, Yurugi S, Iioka H, Niitsuma K, Yasuda Y (2005) Mortality and recurrence rate after pressure ulcer operation for elderly long-term bedridden patients. Ann Plast Surg 54:629-632

46. Han H, Lewis VL Jr, Wiedrich TA, Patel PK (2002) The value of Jamshidi core needle bone biopsy in predicting postoperative osteomyelitis in grade IV pressure ulcer patients. Plast Reconstr Surg 110:118-122

47. Mohler ER (2009) Noninvasive diagnosis of peripheral arterial disease. www.uptodate.com/patients/content/topic.do?topicKey= $\sim$ RcehzKg82g/3J 